Results: Antinuclear antibodies were detected in 2129 out of 2809 systemic sclerosis patients enrolled in the multi-center cohort and $4.2 \%$ of them were negative. There was significant difference between patients with negative and positive ANAs based on gender (29/60 vs 294/1746, $p<0.001$ ). The presence of Raynaud's phenomenon is less common $(71.8 \%$ vs $99.8 \%$, $\mathrm{p}<0.001$ ) in the ANA-negative patients. In addition, compared with ANA-positive patients, the incidence of certain critical organ involvements, including gastroesophageal reflux $(5.6 \%$ vs $18.5 \%, \mathrm{p}=0.002)$, interstitial lung disease $(65.2 \%$ vs $77.9 \%, p=0.015)$ and pulmonary arterial hypertension $(11.5 \%$ vs $29.0 \%, p=0.006$ ) were significantly lower in ANA-negative patients than in the positive group. The proportion of IgG elevation, an indicator of disease activity and severity of inflammation, was significantly lower in the ANA-negative patients than that in the positive group ( $14.3 \%$ vs $41.2 \%, p<0.001)$, while no significant differences were found in other inflammatory indicators and skin scores.

Conclusion: This study describes the clinical features of SSc patients with negative ANAs, which have been rarely mentioned or focused in existing studies. Antinuclear antibody is proved to be strongly associated with the clinical manifestations of systemic sclerosis patients and ANA-negative SSc patients tend to be in relatively milder conditions, including a less common involvement of critical organs and a more temperate inflammatory severity.

References:

[1] Seri, Jeong, Dahae, et al. Diagnostic value of screening enzyme immunoassays compared to indirect immunofluorescence for anti-nuclear antibodies in patients with systemic rheumatic diseases: A systematic review and meta-analysis. [J]. Seminars in arthritis and rheumatism, 2018.

[2] Hesselstrand, R. The association of antinuclear antibodies with organ involvement and survival in systemic sclerosis[J]. Rheumatology, 2003, 42(4):534-540.

[3] Behmanesh F, Amin R, Khajedaluee M, et al. Autoantibody Profile in Systemic Sclerosis[J]. Acta Medica Iranica, 2010, 48(1):12-20.

[4] Hachulla E, Dubucquoi S. Nuclear auto-antibodies: a useful tool for the diagnosis, the classification and the prognosis of systemic sclerosis. [J]. La Revue de Médecine Interne, 2004, 25(6):442-447.

Disclosure of Interests: None declared

DOI: 10.1136/annrheumdis-2020-eular.3168

\section{SAT0327 SEXUAL DYSFUNCTION IN FEMALE SCLERODERMA PATIENTS AND ITS CORRELATION WITH VASCULAR INVOLVEMENT}

Z. Khodamoradi ${ }^{1}$, M. Nazarinia ${ }^{1}$, E. Esmaeilzadeh ${ }^{2} .{ }^{1}$ Shiraz Geriatric Research Center, Shiraz University of Medical Sciences, Division of Rheumatology,

Department of Internal Medicine, Shiraz, Iran (Islamic Republic of); ${ }^{2}$ Division of Rheumatology, Department of Internal Medicine, Shiraz University of Medical Sciences, Division of Rheumatology, Department of Internal Medicine, Shiraz, Iran (Islamic Republic of)

Background: Systemic Sclerosis (Scleroderma, SSc) is an autoimmune disorder characterized by multi-organ dysfunction, which ultimately leads to multiple clinical and psychological complications. Among various complications of scleroderma, sexual dysfunction can be named as a major issue in both male and female patients, which has great impact on quality of life of the patients.

Objectives: Investigating the sexual dysfunction in scleroderma patients and its relation to their vascular involvements.

Methods: A case control study was done on 80 married female scleroderma patients with age between 20-60 years old. Eighty normal individuals adjusted for age, place of living and socioeconomic status were also recruited. Sexual performance in both groups was assessed using FSFI standardized questionnaire, which evaluated it in 6 domains of desire, arousal, lubrication, orgasm, satisfaction, and pain. Micro and macro-vascular involvements of the patients were also determined using Raynaud Condition Score, Echocardiography, physical exam for assessing their digital ulcers and reviewing their medical records for presence of past or present history of renal crisis and thromboembolic events.

Results: The total score of FSFI in the case group was significantly lower compared to control one $(16.68 \pm 6.35,19.69 \pm 6.01$, P-value $<0.001)$. The score was significantly lower in all domains of sexual dysfunction except for pain and lubrication. Moreover, the mean score of FSFI was also found to be significantly lower in limited form of the disease compared to diffuse one $(14.6 \pm 6.9,18.1 \pm$ 5.5 , P-value 0.01 ). No significant association was found between vascular complications and sexual impairment of the scleroderma patients.

Conclusion: This study can be named as the first survey investigating the sexual dysfunction in Iranian female scleroderma patients and assessing its relation with vascular complication of the disease. Thus, it can be a guide for future studies on sexual dysfunction especially in societies with cultural limitations in discussing this issue.

\section{References:}

[1] Bruni C, Raja J, Denton CP, Matucci-Cerinic M. The clinical relevance of sexual dysfunction in systemic sclerosis. Autoimmun Rev 2015; 14(12):1111-5. doi: 10.1016/j.autrev.2015.07.016.

[2] Puchner R, Sautner J, Gruber J, Bragagna E, Trenkler A, Lang G. et al. High Burden of Sexual Dysfunction in Female Patients with Rheumatoid Arthritis: Results of a Cross-sectional Study. J Rheumatol 2019; 46(1):19-26. doi: 10.3899/jrheum.171287.

[3] Lin MC, Lu MC, Livneh H, Lai NS, Guo HR, Tsai TY. Factors associated with sexual dysfunction in Taiwanese females with rheumatoid arthritis. BMC Womens Health 2017; 17(1):12. doi: 10.1186/s12905-017-0363-5.

[4] Frikha F, Masmoudi J, Saidi N, Bahloul Z. Sexual dysfunction in married women with Systemic Sclerosis. Pan Afr Med J 2014; 17:82. doi: 10.11604/ pamj.2014.17.82.3833.

Disclosure of Interests: None declared

DOI: 10.1136/annrheumdis-2020-eular.4084

\begin{tabular}{|l|l}
\hline SAT0328 & OUTCOME OF INTERSTITIAL LUNG DISEASE (ILD) \\
& IN ANTI-PM/SCL PATIENTS WITH SYSTEMIC \\
& SCLEROSIS: RESULTS FROM AN EUSTAR CASE- \\
& CONTROL STUDY.
\end{tabular}

M. G. Lazzaroni ${ }^{1}$, C. Campochiaro ${ }^{2,3}$, E. Marasco ${ }^{4}$, J. De Vries-Bouwstra ${ }^{5}$, F. Franceschini ${ }^{1}$, F. Del Galdo ${ }^{6}$, C. Denton ${ }^{3}$, L. Cavagna ${ }^{4}$, O. Distler ${ }^{7}$, Y. Allanore ${ }^{8}$, P. Airò ${ }^{1}$ on behalf of EUSTAR Co-Authors. ${ }^{1}$ ASST Spedali Civili of Brescia, University of Brescia, Brescia, Italy; ${ }^{2}$ San Raffaele Scientific Institute, Milano, Italy; ${ }^{3}$ Royal Free Hospital and University College London Medical School, London, United Kingdom; ${ }^{4}$ Hospital IRCCS Policlinico S. Matteo Foundation of Pavia, University of Pavia, Pavia, Italy; ${ }^{5}$ Leiden University Medical Centre (LUMC), Leiden, Netherlands; ${ }^{6}$ Leeds Institute of Rheumatic and Musculoskeletal Medicine, University of Leeds, Leeds, United Kingdom; ${ }^{7}$ University Hospital Zurich, Zurich, Switzerland; ${ }^{8}$ University Paris Descartes and Cochin Hospital, Paris, France

Background: The main clinical associations of anti-PM/Scl in Systemic Sclerosis (SSc) so far reported include calcinosis, myositis and interstitial lung disease (ILD). Nevertheless, data regarding the long-term outcome of ILD in these patients are lacking. A single centre Spanish cohort reported a better functional outcome in $14 \mathrm{SSc}$-ILD patients anti-Pm/Scl+ as compared to 49 anti-Topo I after a mean follow-up of 7 years (1).

Objectives: To analyze the long-term outcome of ILD in a large multicentre EUSTAR study dedicated to anti-Pm/Scl SSc patients.

Methods: A case-control study within the EUSTAR cohort collected 165 anti-PM/ Scl+ SSc cases and 257 anti-PM/Scl- SSc controls, matched for sex, cutaneous subset, disease duration, and age at onset. Data for ILD at HRCT were available for $162 / 165$ cases and 249/257 controls. Data for pulmonary function tests (PFT) at the baseline (T0), 1 year after diagnosis (T1) and at the last visit (LV) were analyzed.

Results: A significantly higher frequency of ILD was reported in anti-Pm/Scl+ cases vs anti-Pm/Scl- controls $(62.3 \%$ vs $39.4 \%$, p:<0.0001, OR 95\%, Cl 2.55 1.70-3.83). Complete PFTs data were available for 81/101 ILD anti-Pm/Scl+ cases and 78/98 anti-Pm/Scl- ILD controls, with similar age at onset and female/ male ratio and disease duration at LV $(112 \pm 81$ months vs. $115 \pm 64$ months, $\mathrm{p}: 0.77)$. Diffuse cutaneous involvement was less frequent in cases than in controls $(27.2 \%$ vs. $44.9 \%$, p:0.03).

In ILD cases, \%pFVC tended to improve from T0 $(85.1 \pm 18.3)$ to T1 $(89.5 \pm 16.5$, $\mathrm{p}: 0.045)$ and to LV $(87.9 \pm 16.9, \mathrm{p}: 0.057)$, while in ILD controls remained stable from T0 $(90.4 \pm 18.5)$ to $\mathrm{T} 1(91.1 \pm 16.5, \mathrm{p}: 0.38)$ and significantly declined to LV (85.0 \pm 18.0 , p:0.0002). \%pDLCO remained stable from T0 $(60.5 \pm 16.8)$ to T1 $(60.1 \pm 17.6, p: 0.87)$ and to LV $(60.4 \pm 16.9, p: 0.77)$ in ILD cases, while significantly declined from T0 $(67.0 \pm 18.9)$ to T1 $(62.7 \pm 18.2$, p:0.0016) and to LV $(59.6 \pm 18.4$ $\mathrm{p}<0.0001$ ) in the control group. Mean \%pFVC and \%pDLCO at the 3 time points were not significantly different between the two groups.

Delta \%pFVC (LV-T0) was $2.85 \pm 11.3$ for the anti-Pm/Scl+ group vs $-5.42 \pm 13.4$ in the control group (p:0.0004) with a significant smaller proportion of patients with FVC loss $\geq 10 \%$ from T0 to LV in the anti-PM/Scl group (12.3\% vs. $39.7 \%$, p:0.0001). Delta \%pDLCO (LV-T0) was $-0.13 \pm 10.8$ for the anti-PM/Scl+ group vs $-7.38 \pm 14.6$ in the control group ( $p: 0.0015$ ), with a significant smaller proportion of patients with DLCO loss $\geq 10 \%$ from T0 to LV in the anti-PM/Scl+ group (13.6\% vs. $42.3 \%, p<0.0001)$.

Conclusion: In this multicenter real-life study, the long-term pulmonary functional outcome in SSc-ILD patients with anti- $\mathrm{Pm} / \mathrm{Scl}$ positivity seems to be more favorable than in patients without anti- $\mathrm{Pm} / \mathrm{Scl}$ antibodies. 


\section{References:}

[1] Guillen-Del Castillo A, Semin Arthritis Rheum 2014, 44 (3), 331-7.

Disclosure of Interests: : Maria Grazia Lazzaroni: None declared, Corrado Campochiaro Speakers bureau: Novartis, Pfizer, Roche, GSK, SOBI, Emiliano Marasco: None declared, Jeska de Vries-Bouwstra: None declared, Franco Franceschini: None declared, Francesco Del Galdo: None declared, Christopher Denton Grant/research support from: GlaxoSmithKline, CSL Behring, and Inventiva, Consultant of: Medscape, Roche-Genentech, Actelion, GlaxoSmithKline Sanofi Aventis, Inventiva, CSL Behring, Boehringer Ingelheim, Corbus Pharmaceuticals, Acceleron, Curzion and Bayer, Lorenzo Cavagna: None declared, Oliver Distler Grant/research support from: Grants/Research support from Actelion, Bayer, Boehringer Ingelheim, Competitive Drug Development International Ltd. and Mitsubishi Tanabe; he also holds the issued Patent on mir-29 for the treatment of systemic sclerosis (US8247389, EP2331143)., Consultant of: Consultancy fees from Actelion, Acceleron Pharma, AnaMar, Bayer, Baecon Discovery, Blade Therapeutics, Boehringer, CSL Behring, Catenion, ChemomAb, Curzion Pharmaceuticals, Ergonex, Galapagos NV, GSK, Glenmark Pharmaceuticals, Inventiva, Italfarmaco, iQvia, medac, Medscape, Mitsubishi Tanabe Pharma MSD, Roche, Sanofi and UCB, Speakers bureau: Speaker fees from Actelion, Bayer, Boehringer Ingelheim, Medscape, Pfizer and Roche, Yannick Allanore Grant/research support from: BMS, Inventiva, Roche, Sanofi, Consultant of: Actelion, Bayer AG, BMS, BI, Paolo Airò: None declared DOI: 10.1136/annrheumdis-2020-eular.4890

\begin{tabular}{|l|l|}
\hline SAT0329 & IS THE RATE OF LUNG FUNCTION DECLINE THE \\
SAME IN PATIENTS WITH SYSTEMIC SCLEROSIS- \\
ASSOCIATED ILD (SSC-ILD) WHO EXPERIENCE \\
WEIGHT LOSS? DATA FROM THE SENSCIS TRIAL
\end{tabular}

A. Lescoat ${ }^{1}$, S. Jouneau ${ }^{2}$, B. Crestani ${ }^{3}$, G. Riemekasten ${ }^{4}$, Y. Kondoh ${ }^{5}$, V. Smith ${ }^{6}$, N. Patel ${ }^{7}$, J. Huggins ${ }^{8}$, C. Stock ${ }^{9}$, M. Gahlemann ${ }^{10}$, M. Alves ${ }^{11}$, C. Denton ${ }^{12}$. ${ }^{1} \mathrm{CHU}$ South Hospital, Internal Medicine, Rennes, France; ${ }^{2}$ Department of Respiratory Medicine, Competences Centre for Rare Pulmonary Diseases, CHU Rennes, Univ Rennes, Rennes, France; ${ }^{3}$ Hôpital Bichat, Pneumologie, Paris, France; ${ }^{4}$ University Hospital Charité, Rheumatology and Clinical Immunology, Berlin, and University Hospital Schleswig-Holstein, Rheumatology, Lübeck, Germany; ${ }^{5}$ Tosei General Hospital, Department of Respiratory Medicine and Allergy, Seto, Japan; ${ }^{6}$ Department of Rheumatology, Ghent University Hospital, Ghent, Belgium; Department of Internal Medicine, Ghent University, Ghent, Belgium; ${ }^{7}$ Columbia University College of Physicians and Surgeons/New YorkPresbyterian Hospital, Division of Pulmonary, Allergy, and Critical Care Medicine, New York, NY, United States of America; ${ }^{8}$ Medical University of South Carolina, Charleston, South Carolina, United States of America; ${ }^{9}$ Boehringer Ingelheim Pharma GmbH \& Co. KG, Ingelheim, Germany; ${ }^{10}$ Boehringer Ingelheim (Schweiz) GmbH, Basel, Switzerland; ${ }^{11}$ Boehringer Ingelheim International $\mathrm{GmbH}$, Ingelheim am Rhein, Germany; ${ }^{12}$ Centre for Rheumatology and Connective Tissue Diseases, University College London Division of Medicine, London, United Kingdom

Background: In the SENSCIS trial, nintedanib reduced the progression of SScILD vs placebo, as shown by a lower rate of decline in forced vital capacity (FVC). The adverse event (AE) profile of nintedanib was characterised mainly by gastrointestinal (Gl) events, including weight loss.

Objectives: Assess FVC decline and AEs in subgroups by weight loss $\leq 5 \%$ vs $>5 \%$ over 52 weeks in the SENSCIS trial.

Methods: Patients with SSc-ILD with first non-Raynaud symptom $<7$ years before screening and $\geq 10 \%$ fibrosis of the lungs on an HRCT scan were randomised to nintedanib or placebo. In a non-randomised comparison, we analysed the rate of decline in FVC (mL/year) and AEs over 52 weeks in subgroups by weight loss ( $\leq 5 \%$ vs $>5 \%$ ) over 52 weeks.

Results: In the nintedanib $(n=288)$ and placebo $(n=288)$ groups, respectively, $112(38.9 \%)$ and $43(14.9 \%)$ patients had weight loss $>5 \%$ over 52 weeks. At baseline, patients with weight loss $>5 \%$ over 52 weeks had a higher mean age ( 57.0 vs 52.9 years), greater proportion of females $(81.3 \%$ vs $72.9 \%)$, and similar mean BMI (26.5 vs $25.7 \mathrm{~kg} / \mathrm{m}^{2}$, respectively) and FVC \% predicted $(71.0 \%$ vs $73.1 \%$, respectively) vs patients with weight loss $\leq 5 \%$. In the placebo group, the mean (SE) annual rate of decline in FVC was similar between patients who had weight loss $\leq 5 \%$ and $>5 \%$ over 52 weeks $(-92.7$ [14.7] mL/year and -96.4 [34.9] $\mathrm{mL} /$ year, respectively). The estimated annual rate of decline in FVC was lower in patients treated with nintedanib than placebo, with between-group differences in patients who had weight loss $\leq 5 \%$ and $>5 \%$ of $49.9 \mathrm{~mL} /$ year $[95 \% \mathrm{Cl} 4.2,95.6]$ ) and $30.2 \mathrm{~mL} /$ year $[95 \% \mathrm{Cl}-50.5,110.9]$ ), respectively, with no evidence of heterogeneity between subgroups by weight loss ( $\mathrm{p}=0.68$ for interaction). Standardised differences in baseline values of potential confounders were $<0.2$ (indicating negligible differences). The most frequent $\mathrm{AEs}$ in patients treated with nintedanib were diarrhoea $(74.4 \%$ and $77.7 \%$ of patients with weight loss $\leq 5 \%$ and $>5 \%$, respectively), nausea (30.1\% and $33.9 \%$, respectively) and vomiting (19.3\% and $33.3 \%$, respectively). In the nintedanib and placebo groups, respectively, AEs leading to discontinuation of study drug occurred in $17.0 \%$ and $8.6 \%$ of patients with weight loss $\leq 5 \%$, and $14.3 \%$ and $9.3 \%$ of patients with weight loss $>5 \%$ over 52 weeks.

Conclusion: In the SENSCIS trial in patients with SSc-ILD, a greater proportion of patients treated with nintedanib than placebo had weight loss $>5 \%$ over 52 weeks. The rate of decline in FVC was numerically lower in the nintedanib group than in the placebo group both in patients with weight loss $\leq 5 \%$ and $>5 \%$ ove 52 weeks. AEs leading to discontinuation of nintedanib were not more frequent in patients with weight loss $>5 \%$ vs $\leq 5 \%$.

\section{References:}

Figure. Rate of decline in FVC in subgroups by weight loss over 52 weeks in the SENSCIS trial

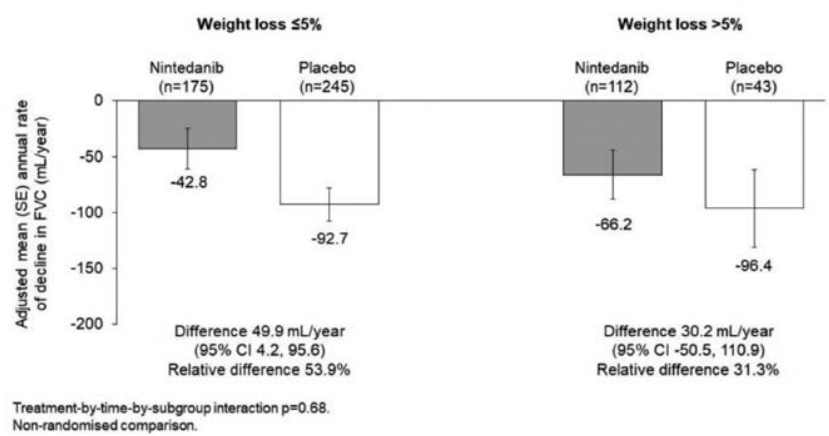

Disclosure of Interests: : Alain LESCOAT: None declared, Stéphane Jouneau Grant/research support from: AIRB, Boehringer Ingelheim, LVL Medical, Novartis, Roche, Bellorophon Therapeutics, Biogen, Fibrogen, Galecto Biotech, Gilead Sciences, Pharm-Olam, Pliant Therapeutics, Savara Pharmaceuticals/Serendex Pharmaceuticals, Consultant of: Actelion, AIRB, AstraZeneca, Bristol-Myers Squibb, Boehringer Ingelheim, Chiesi, Genzyme, GlazoSmithKline, LVL Medical Mundipharma, Novartis, Pfizer, Roche, Sanofi, Bruno Crestani Grant/research support from: AstraZeneca, Bristol-Myers Squibb, Boehringer Ingelheim, Novartis, Roche, Sanofi, Consultant of: AstraZeneca, Bristol-Myers Squibb, Boehringer Ingelheim, Roche, Sanofi, Speakers bureau: AstraZeneca, Boehringer Ingelheim, Roche, Sanofi, Gabriela Riemekasten Consultant of: Cell Trend GmbH Janssen, Actelion, Boehringer Ingelheim, Speakers bureau: Actelion, Novartis, Janssen, Roche, GlaxoSmithKline, Boehringer Ingelheim, Pfizer, Yasuhiro Kondoh Consultant of: Boehringer Ingelheim, Asahi Kasei Pharma, Janssen, Shionogi, Speakers bureau: Boehringer Ingelheim, Asahi Kasei Pharma, Janssen, Eisai, KYORIN, Mitsubishi Tanabe Pharma, Novartis, Shionogi, Vanessa Smith Grant/research support from: The affiliated company received grants from Research Foundation - Flanders (FWO), Belgian Fund for Scientific Research in Rheumatic diseases (FWRO), Boehringer Ingelheim Pharma GmbH \& Co and Janssen-Cilag NV, Consultant of: Boehringer-Ingelheim Pharma GmbH \& Co, Speakers bureau: Actelion Pharmaceuticals Ltd, Boehringer-Ingelheim Pharma $\mathrm{GmbH} \& \mathrm{Co}$ and UCB Biopharma Sprl, Nina Patel Grant/research support from: Boehringer Ingelheim, Consultant of: Boehringer Ingelheim, Speakers bureau: Genentech, John Huggins Consultant of: I was a site PI for the SENSCIS tria for Boehringer Ingelheim, Christian Stock Employee of: Employee of Boehringer Ingelheim, Martina Gahlemann Employee of: Employee of Boehringer Ingelheim, Margarida Alves Employee of: Employee of Boehringer Ingelheim, Christopher Denton Grant/research support from: GlaxoSmithKline, CSL Behring, and Inventiva, Consultant of: Medscape, Roche-Genentech, Actelion, GlaxoSmithKline, Sanofi Aventis, Inventiva, CSL Behring, Boehringer Ingelheim, Corbus Pharmaceuticals, Acceleron, Curzion and Bayer DOI: 10.1136/annrheumdis-2020-eular.3535

\section{SAT0330 NEW IMMUNOMODULATORY COMBINATION THERAPIES IN PATIENTS WITH SYSTEMIC SCLEROSIS: A RETROSPECTIVE CROSS-SECTIONAL STUDY}

J. Qiao' ${ }^{1}$, S. X. Zhang ${ }^{1}$, T. T. Zhang ${ }^{1}$, J. Zhang ${ }^{1}$, M. T. Qiu ${ }^{1}$, R. Zhao ${ }^{1}$, M. J. Chang ${ }^{1}$, Y. Li ${ }^{1}$, J. Luo ${ }^{1}$, G. Y. Liu ${ }^{1}$, C. Gao ${ }^{1,2}, \underline{\text { X. Li }}{ }^{1}$. ${ }^{1}$ The Second Hospital of Shanxi Medical University, Rheumatology, Taiyuan, China; ${ }^{2}$ Brigham and Women's Hospital, Harvard Medical School, Boston, United States of America

Background: Systemic sclerosis (scleroderma, SSc) is a rare complex connective tissue disease associated with high mortality and high morbidity ${ }^{1}$. Active SSc 